\title{
In vivo stability and biocompatibility of implanted calcium alginate disks
}

\author{
Elizabeth A. Nunamaker, Erin K. Purcell, Daryl R. Kipke \\ Department of Biomedical Engineering, University of Michigan, Ann Arbor, Michigan 48109-2099
}

Received 5 June 2006; revised 15 October 2006; accepted 3 November 2006

Published online 26 June 2007 in Wiley InterScience (www.interscience.wiley.com). DOI: 10.1002/jbm.a.31275

\begin{abstract}
Alginate is a commonly used biomedical hydrogel whose in vivo degradation behavior is only beginning to be understood. The use of alginate in the central nervous system is gaining popularity as an electrode coating, cell encapsulation matrix, and for duraplasty. However, it is necessary to understand how the hydrogel will behave in vivo to aid in the development of alginate for use as a neural interface material. The goal of the current study was to compare the rheological behavior of explanted alginate disks and the inflammatory response to subcutaneously implanted alginate hydrogels over a 3month period. Specifically, the effects due to (1) in situ gelling, (2) diffusion gelling, and (3) use of a poly-L-lysine (PLL) coating were investigated. While all samples' com-
\end{abstract}

plex moduli decreased $80 \%$ in the first day, in situ gelled alginate was more stable for the first week of implantation. The PLL coating offered some stability increases for diffusion gelled alginate, but the stability in both conditions remained significantly lower than that in in situ gelled alginate. There were no differences in biocompatibility that clearly suggested one gelation method over another. These results indicate that in situ gelation is the preferred method in neural interface applications where stability is the primary concern. (C) 2007 Wiley Periodicals, Inc. J Biomed Mater Res 83A: 1128-1137, 2007

Key words: hydrogel; alginate; degradation; biocompatability

\section{INTRODUCTION}

Recently, there have been several reports using alginate in advanced neural interface technologies. These include microelectrode coatings, cell scaffolds, neural stem cell encapsulation, and development of an artificial dura mater. ${ }^{1-7}$ Alginate shows promise and utility as a material in the development of advanced neural interfaces. Its long-term biocompatibility, mild reaction conditions that allow hydrogel cross-linking while in direct contact with neural tissues, and minimal risk of seizure activity in rats are especially important considering the imminent and prolonged contact of the hydrogel components with neural tissues. ${ }^{1,8-14}$ Unfortunately, little is known about the long-term stability of alginate, which may be important to the lifetime of advanced neural prosthetic devices incorporating this material.

No benefit of any kind will be received either directly or indirectly by the authors.

Correspondence to: D.R. Kipke; e-mail: dkipke@umich. edu

Contract grant sponsor: Michigan Economic Development Corridor

(C) 2007 Wiley Periodicals, Inc.
Alginate is a naturally occurring polysaccharide copolymer that can be used to create hydrogels with a broad range of material properties. Derived from brown algae, alginate is composed of blocks of both $\beta$-D-mannuronic acid (M) and $\alpha$-L-guluronic acid (G) linked together by 1,4-bonds. ${ }^{15,16}$ Alginate is water soluble and can be ionically cross-linked by various divalent ions. ${ }^{17}$ Currently $\mathrm{Ca}^{2+}$ is preferred to crosslink alginate for biomedical applications because of the mild reaction conditions compared to the cellular toxicity of both $\mathrm{Ba}^{2+}$ and $\mathrm{Sr}^{2+} \cdot{ }^{10,17-19}$ In the process of cross-linking, the calcium ions interact with the carboxyl groups of the $\mathrm{G}$ blocks of two neighboring alginate chains forming an "egg box" orientation. ${ }^{20}$ Because of the large variety of alginate sources and $\mathrm{G}$ and $\mathrm{M}$ block ratios, the properties of the resulting cross-linked gels can be highly variable. Alginate with a higher $\mathrm{G}$ content typically results in stronger gels; while alginate with a higher $\mathrm{M}$ content yields more flexible gels. ${ }^{21}$

Two methods of gelation have been extensively described and used to create alginate hydrogels: diffusion gelling and in situ gelling (Fig. 1). ${ }^{10,17,19,22-30}$ $\mathrm{CaCl}_{2}$ is a commonly used calcium source that relies on diffusion to cross-link alginate. $\mathrm{Ca}^{2+}$ can readily dissociate from the $\mathrm{Cl}^{-}$to cross-link the first carboxyl 
A
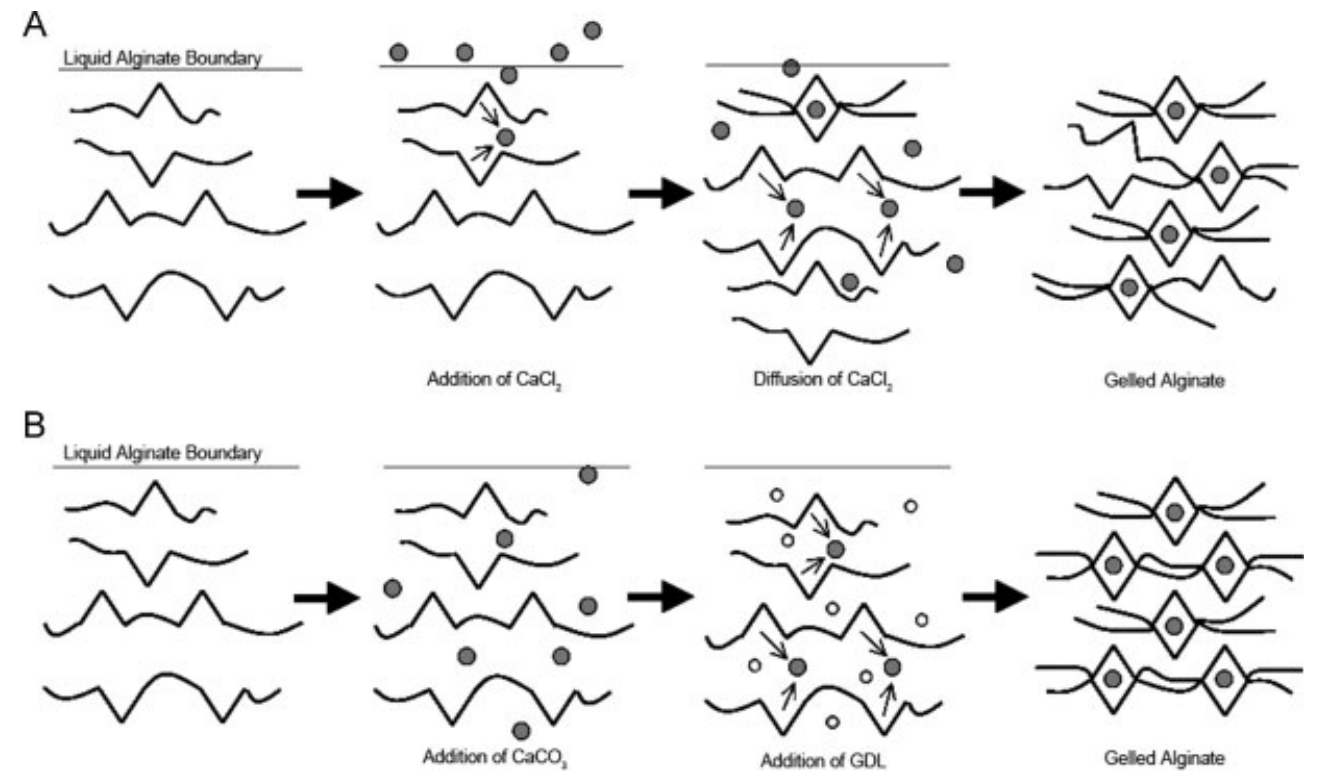

Figure 1. Diffusion and in situ gelling of liquid alginate. (A) Diffusion gelling. Calcium ions diffuse through the liquid alginate boundary, cross-linking alginate strands as the ions move through the volume of alginate. Cross-links are not uniformly distributed throughout the gel. (B) In situ gelling. $\mathrm{CaCO}_{3}$ is mixed with alginate to create a homogeneous mixture (black circles). D-Glucono- $\delta$-lactone (GDL, grey circles) is added to acidify the solution and release calcium ions, making them available for cross-linking. The resultant hydrogel has a uniform distribution of cross-links.

groups with which it comes into contact. This rapid reaction creates a skin around the volume of liquid alginate. Subsequently, the calcium ions diffuse inward (i.e., diffusion gelling), increasing the skin's thickness as the alginate bolus is cross-linked. ${ }^{31,32}$ Although this results in rapid gel formation, the resulting hydrogel structure is highly variable. ${ }^{12,32}$ Despite this, diffusion gelling remains an ideal approach that is widely used for rapidly encapsulating cells in microspheres of alginate. ${ }^{23,33-37}$

$\mathrm{CaCO}_{3}$ and $\mathrm{CaSO}_{4}$ are commonly used $\mathrm{Ca}^{2+}$ sources that rely on internal gelling through the release of calcium ions in situ. In the case of $\mathrm{CaCO}_{3}$, poorly soluble calcium ions in the form of $\mathrm{CaCO}_{3}$ are homogeneously mixed with alginate and then the $\mathrm{Ca}^{2+}$ is solubilized by the addition of catalyst, such as D-glucono- $\delta$-lactone (GDL). GDL slowly acidifies the alginate: $\mathrm{CaCO}_{3}$ solution, driving the release of $\mathrm{Ca}^{2+} \cdot 26,38$ Calcium ions bind to the nearest available carboxyl groups on the alginate molecules, cross-linking the hydrogel in a spatially uniform manner. This method can be time intensive due to the time required for the hydrolysis of GDL and subsequent calcium release; however, the resultant hydrogel has a more uniform and reproducible structure. ${ }^{23,26,38}$

Diffusion gelled alginate has previously been shown to destabilize both in vitro and in vivo. ${ }^{39-41}$ Prolonged exposure to sodium ions decreases both compressive and shear stiffness of alginate, suggesting that physiological conditions will soften the gel over a time period of up to 7 days after gelation. ${ }^{40}$ Further, LeRoux et al. showed that high $\mathrm{M}$ alginate hydrogels exhibited a significant decrease in complex modulus but retained solid-like behavior after 7 days of exposure to $0.15 \mathrm{M} \mathrm{NaCl}$ and $1.8 \mathrm{mM}$ $\mathrm{CaCl}_{2}{ }^{40}$ Kong et al., however, demonstrated the superior retention of elastic modulus of high $\mathrm{G}$ alginate over high $\mathrm{M}$ alginate implanted up to 35 days. ${ }^{39}$ This effect is due to calcium's higher affinity for $G$ sites than $M$ sites, resulting in a more dense distribution of cross-links in a high G concentration hydrogels. This dense distribution of cross-links enhances the stability of high $G$ alginate hydrogels after prolonged exposure to the inert electrolytes found in vivo, thereby decreasing the effect of ion exchange at the cross-link site. ${ }^{39}$ While these previous studies support our current investigations of high $G$ alginate stability in vivo, there are currently no studies that investigate stability differences based on gelation method.

Poly-L-lysine (PLL) coatings are commonly used to stabilize alginate capsules and provide a barrier to immune system components such as IgG in cell encapsulation applications. ${ }^{42,43}$ Unfortunately, there is evidence that the PLL coating itself may be toxic to encapsulated cells and cause an unfavorable foreign body response. ${ }^{4-47}$ Additionally, claims that PLL coatings improve alginate mechanical stability have been based on in vitro findings. PLL-coated alginate capsules seeded with proliferative cells remained intact for longer periods of time compared to noncoated capsules in culture..$^{37,48}$ Given the potential toxicity of PLL on encapsulated cells, these results may be confounded by a slight reduction in 
TABLE I

The Gelation Conditions for All Hydrogels to be Implanted Subcutaneously and Analyzed via Rheology or Histology

\begin{tabular}{lcccccc}
\hline & Experiment & Alginate Volume $(\mathrm{ml})$ & Cross-linker Volume & GDL $(\mathrm{mg})$ & PLL Coating & $n$ per Time Point \\
\hline $\mathrm{CaCO}_{3}$ & Histology & 0.5 & $5 \mathrm{mg}$ & 7.1 & No & No \\
$\mathrm{CaCl}_{2}$ & Rheology & 2 & $20 \mathrm{mg}$ & 28.4 & No & 5 \\
$\mathrm{CaCl}_{2} /$ PLL & Histology & 0.5 & $0.5 \mathrm{~mL} ; 200 \mathrm{mM}$ & 0 & No & 6 \\
& Rheology & 2 & $2 \mathrm{~mL} ; 200 \mathrm{mM}$ & 0 & 0.5 & 6 \\
& Ristology & 0.5 & $0.5 \mathrm{~mL} ; 200 \mathrm{mM}$ & 0 & Yes & 5 \\
\hline
\end{tabular}

cell proliferation, which could in turn result in more stable capsules. While quantitative testing has revealed that increased PLL membrane thickness corresponds with more mechanically stable nonseeded capsules in vitro, quantitative in vivo mechanical testing has not been reported in the literature. ${ }^{49}$ Given that polycation coatings remain controversial after 25 years of research due to questionable biocompatibility, and that quantitative in vivo material testing data is lacking, there is a clear need to explore the in vivo biocompatibility and stability of PLL-coated alginate in comparison to uncoated alginate. ${ }^{50}$

In the current study, we investigated alginate disks cross-linked with $\mathrm{CaCl}_{2}$ or $\mathrm{CaCO}_{3}$ and measured each of the following parameters over time: (1) weight changes, (2) complex modulus, (3) loss angle, and (4) biological response to the subcutaneously implanted disks. Additionally, we investigated the effects of PLL coatings on $\mathrm{CaCl}_{2}$ cross-linked alginate disks on these same four parameters. The goal of this paper was to identify stability and biocompatibility differences in diffusion gelled and in situ gelled alginate samples and evaluate the necessity of PLL coatings for enhanced stability. Specifically, we wanted to identify any advantages (biocompatibility or stability) of the specific gelation methods and hydrogel coating to guide future development of advanced neural interface technologies.

\section{MATERIALS AND METHODS}

\section{Alginate hydrogel preparation}

High G content sodium alginate $(66 \%$ G acid) was acquired from Novamatrix (Pronova UP LVG, Drammen, Norway). Noncoated hydrogels were prepared as previously described, but with sterilized chemical components. ${ }^{7}$ Briefly, $1.95 \mathrm{wt} \% 43 \mathrm{mPa}$ s alginate was cross-linked following one of the reaction schemes outlined in Figure 1. The gelation method and volume of the resulting hydrogels for each specific experiment is outlined in Table I. Rheology hydrogels were created in a sterile $10 \mathrm{~mL}$ beaker: $2 \mathrm{~mL}$ alginate was reacted with (1) $100 \mathrm{mM} \mathrm{CaCO}_{3}$ (Sigma, St. Louis, $\mathrm{MO}$ ) and $80 \mathrm{mM}$ GDL (Sigma, St. Louis, MO) (final concentrations), or (2) $2 \mathrm{~mL} 200 \mathrm{mM} \mathrm{CaCl}$ (Sigma, St. Louis, MO) (Table I). Histology hydrogels were created in a single well of a sterile 24-well tissue culture plate: $500 \mu \mathrm{L}$ of alginate was reacted with (1) $100 \mathrm{mM} \mathrm{CaCO}_{3}$ and $80 \mathrm{mM}$ GDL (final concentrations), or (2) $500 \mu \mathrm{L} 200 \mathrm{mM} \mathrm{CaCl}$ (Table I). Hydrogels created via in situ gelling $\left(\mathrm{CaCO}_{3}\right)$ were well mixed before addition of GDL to ensure homogeneous distribution of cross-links throughout the gel. Hydrogels created via diffusion gelling $\left(\mathrm{CaCl}_{2}\right)$ were cross-linked by slowly pipetting the $\mathrm{CaCl}_{2}$ solution onto the bolus of alginate. All gels were allowed to fully cross-link under sterile conditions for $12 \mathrm{~h}$ prior to implantation.

To test the effect of a PLL coating, $\mathrm{CaCl}_{2}$ hydrogels made for rheology and histology were additionally coated with PLL $\left(\mathrm{CaCl}_{2} / \mathrm{PLL}\right)$ as described by Strand et al. (Table I). ${ }^{51}$ Briefly, alginate disks were rinsed in physiological saline and incubated for $10 \mathrm{~min}$ in $0.1 \%$ PLL in saline. PLL$\mathrm{HCl}$ (15,000-30,000 MW) was obtained from Sigma (St. Louis, MO). Disks were rinsed again in saline and incubated for $10 \mathrm{~min}$ in $0.1 \%$ alginate in saline. Disks were rinsed a final time in saline prior to implantation. To maintain similarity to PLL coated hydrogels, $\mathrm{CaCl}_{2}$ gels were also rinsed in saline several times prior to implantation.

\section{Surgery}

Alginate hydrogel stability and biocompatibility were tested in $300 \mathrm{~g}$ Sprague Dawley rats (Charles River Laboratories, Wilmington, MA). All procedures were approved by the University of Michigan Committee on Use and Care of Animals. Anesthesia was administered using an intraperitoneal injection of an anesthetic cocktail (comprised of Ketamine, Xylazine, and Acepromazine, each at concentrations of $100 \mathrm{mg} / \mathrm{mL}$ and a respective mixing ratio of $5: 0.5: 1$ ) administered at $0.15 \mathrm{~mL} / 100 \mathrm{~g}$ body weight. Rats were indicated for rheology or histology before surgical implantation due to the size difference in the gels. All hydrogels were implanted in separate subcutaneous pouches created on the abdomen and the skin was securely closed with surgical staples.

Forty-eight rats were used in the rheology study, each receiving four hydrogels. The hydrogel conditions $\left(\mathrm{CaCO}_{3}\right.$, $\mathrm{CaCl}_{2}$, or $\mathrm{CaCl}_{2} / \mathrm{PLL}$ ) were chosen at random for each animal, but no animal received more than two gels of the same condition. At the time of hydrogel recovery, the rats were deeply anesthetized with anesthetic cocktail $(0.3 \mathrm{~mL} / 100 \mathrm{~g}$ body weight) and then euthanized with a cardiac injection of $1 \mathrm{~mL}$ Fatal-Plus ${ }^{\mathbb{R}}$ (Pentobarbital $390 \mathrm{mg} / \mathrm{mL}$, Vortech Pharmaceutical, Dearborn, MI). Five hydrogels per condition were recovered at each time point $(1,3,5,7,14,21$, and 90 days) by removing the hydrogel from the subcutaneous 
pouch. All hydrogels were weighed and rheological measurements taken immediately following explantation.

Twelve rats were utilized in the histology study. Each rat was implanted with two gels per condition for all conditions $\left(\mathrm{CaCO}_{3}, \mathrm{CaCl}_{2}\right.$, and $\left.\mathrm{CaCl}_{2} / \mathrm{PLL}\right)$, resulting in a total of six implants per animal. At each predetermined time point $(7,14,21$, and 90 days), the hydrogels were recovered from three rats per time point to evaluate the biological response to the implants. Rats were euthanized in the same manner as described for the rheology study. The tissue and alginate disk were explanted en bloc and treated with Bouin's Fixative for $24 \mathrm{~h}$.

\section{Disk weight change}

To determine the swelling/shrinking behavior of the hydrogels, all gels indicated for rheology were weighed prior to implantation. Immediately upon explantation, all gels were weighed again to determine an increase or decrease in disk weight. The average weight difference and standard error were calculated for each hydrogel condition $\left(\mathrm{CaCO}_{3}, \mathrm{CaCl}_{2}\right.$, and $\left.\mathrm{CaCl}_{2} / \mathrm{PLL}\right)$ and time point (1, $3,5,7,14,21$, and 90 days).

\section{Rheology: complex modulus and loss angle}

The viscoelastic behavior of the hydrogels was tested with a parallel plate rheometer (AR 550, TA Instruments, New Castle, DE) using a $25-\mathrm{mm}$ plate at $37^{\circ} \mathrm{C}$. The alginate samples were compressed to $10 \%$ and subjected to a $1 \%$ strain across a frequency sweep of 1-100 rad/s at each level. Sandpaper (150-grit) was placed on the plate surfaces to minimize the occurrence of slip at the plate/sample interface. The storage $\left(G^{\prime}\right)$ and loss moduli $\left(G^{\prime \prime}\right)$ were calculated by the rheometer and recorded for further analysis.

The complex modulus $\left(G^{*}\right)$, which represents the frequency-dependent stiffness of the hydrogel, and loss angle, $\delta$, which provides a relative measure of viscous effects to elastic effects in a material, were calculated as previously described. ${ }^{7}$ Low values of $\delta$ indicate minimal internal damping, a result of energy dissipation and internal friction in deformation cycles due to internal entanglements and cross-link density $\left(\delta=0^{\circ}\right.$, elastic solid; $\delta=90^{\circ}$, Newtonian viscous fluid). ${ }^{40}$ The response of alginate to shear is a good indicator of the fatigue resistance and how it will perform in vivo. Brain tissue typically exhibits a complex modulus ranging from 1 to $24 \mathrm{kPa}$ and alginate is expected to remain in this range. ${ }^{52}$ For application in or on the brain, the frequency range of $1-5 \mathrm{~Hz}$ was chosen, as this represents the heart rate frequency range of humans and rats and therefore the highest oscillation rate the gels would be exposed to in vivo. Average $G^{*}$ and $\delta$ and the respective standard errors at 1 and $5 \mathrm{~Hz}$ were calculated.

\section{Histology}

Tissue samples were dehydrated in a graded series of ethanol washes $(10-70 \%)$, embedded in paraffin, and sectioned with a microtome. Two 8 - $\mu \mathrm{m}$-thick sections per implant were each stained with hematoxylin and eosin (H\&E) or Masson's trichrome (MT) based on previous reports. ${ }^{53,54} \mathrm{H \& E}$-stained sections were used to detect the presence of inflammatory response cells.

MT-stained sections were used to assess the degree of cell infiltration surrounding the implant on a qualitative scale $(0-4)$, and to quantitatively evaluate the thickness of the encapsulating collagen layer as described. ${ }^{41,53,55}$ The scoring levels indicated increasing levels of infiltration: 0 no cells present on the surface of the alginate; 1 - less than $50 \%$ of the surface area of alginate covered by cellular attachment indicating minor infiltration; 2 - greater than $50 \%$ of the surface area of alginate covered by cellular attachment indicating moderate infiltration; $3-100 \%$ of the surface area of alginate covered by cellular attachment indicated severe infiltration. Due to the amount of variation seen in both of these measurements, infiltration scores were taken from 10 separate hydrogel fragments in different regions of the same tissue section. Similarly, collagen thickness was measured around 10 separate hydrogel fragments by taking eight equally spaced measurements around each fragment. The repeated measures for each parameter (cell infiltration and encapsulation thickness) for a given tissue section were averaged, resulting in one infiltration score and one encapsulation thickness per section. For each parameter the results for a condition then were combined to calculate the average and standard error for each condition $\left(7,14,21\right.$, and 90 days for $\mathrm{CaCO}_{3}, \mathrm{CaCl}_{2}$, and $\left.\mathrm{CaCl}_{2} / \mathrm{PLL}\right)$.

\section{Statistics}

All results were analyzed for normality and subsequently analyzed by the appropriate ANOVA (parametric or nonparametric). When indicated, the appropriate post hoc test was utilized to determine significant differences in the data. The statistical test used in each situation is reported with the results for each section of the study.

\section{RESULTS}

\section{Disk weight change}

Because of the nature of gelation and coating of the hydrogels, the gels had significantly different initial weights (Dunn's comparison test). $\mathrm{CaCO}_{3}$ reacted alginate was significantly heavier than $\mathrm{CaCl}_{2}$ or $\mathrm{CaCl}_{2} /$ PLL reacted alginate $(p<0.001$, Fig. $2 \mathrm{~A})$. $\mathrm{CaCl}_{2} / \mathrm{PLL}$ hydrogels were also significantly heavier than $\mathrm{CaCl}_{2}$ reacted alginate $(p<0.001$, Fig. $2 \mathrm{~A})$ due to the PLL coating of the hydrogel.

Hydrogel weights varied with duration of implant (Fig. $2 \mathrm{~B}$ ). $\mathrm{CaCO}_{3}$ reacted hydrogels trended towards a continual decrease in weight over the entire time course $\left(p<0.001\right.$, Kruskal-Wallis ANOVA). $\mathrm{CaCl}_{2}$ and $\mathrm{CaCl}_{2} / \mathrm{PLL}$ gels both decreased in weight on day 1 , but subsequently demonstrated a significant weight gain up to day 7 before significantly decreasing 
A

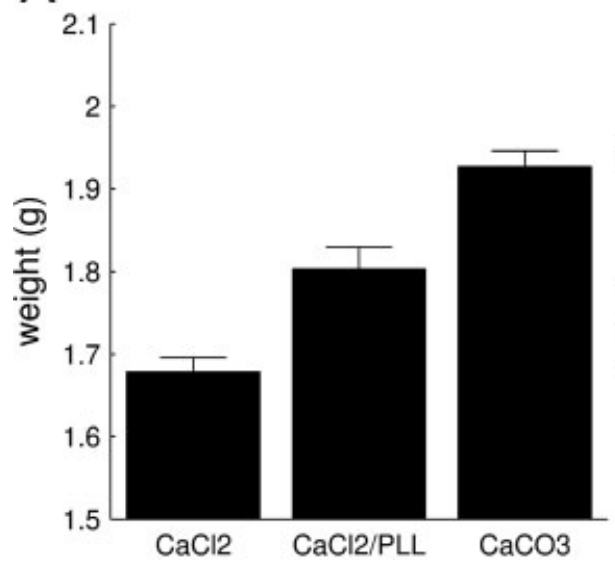

B

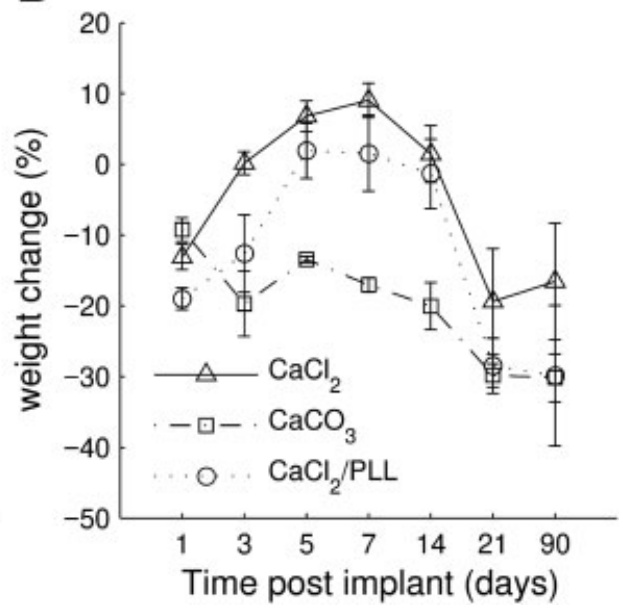

Figure 2. Differences in hydrogel weight. (A) On day 0 , the alginate's weights were significantly different for each condition. $\mathrm{CaCO}_{3}$ reacted gels were the heaviest initially $(p<0.001) \cdot \mathrm{CaCl}_{2} / \mathrm{PLL}$ hydrogel were significantly heavier than $\mathrm{CaCl}_{2}$ reacted gels on day $0(p<0.001)$. (B) Hydrogel weight changes with time. All of the hydrogels decreased in weight on day 1 ; however, the weights of the $\mathrm{CaCl}_{2}$ and $\mathrm{CaCl}_{2} / \mathrm{PLL}$ hydrogels then increased until day 7. After day 7, these gels begin to decrease in weight for the remainder of the time course. $\mathrm{CaCO}_{3}$ hydrogels decreased in weight over the entire time course. $n=5$.

in weight for the remainder of the implant duration $(p$ $<0.005$, Kruskal-Wallis ANOVA). Both $\mathrm{CaCO}_{3}$ and $\mathrm{CaCl}_{2} /$ PLL hydrogels decreased approximately $30 \mathrm{wt}$ $\%$ by day 90 , but $\mathrm{CaCl}_{2}$ only decreased $17 \%$.

\section{Rheology: complex modulus and loss angle}

$G^{*}$ varied with both experimental condition and time. No significant difference in $G^{*}$ existed between experimental conditions initially ( $p=0.099$, ANOVA). A large decrease ( $>80 \%$ ) in $G^{*}$ was determined for all experimental conditions for 1 day post implant $(p<$ 0.001 , Fig. 3A). By day $3, G^{*}$ was significantly greater for $\mathrm{CaCO}_{3}$ reacted alginate than $\mathrm{CaCl}_{2}$ or $\mathrm{CaCl}_{2} / \mathrm{PLL}$. This phenomena continued until day 7 ( $p<0.01$, Fig. $3 \mathrm{~A})$, after which no significant differences in $G^{*}$ existed between the hydrogels. $\mathrm{CaCl}_{2} / \mathrm{PLL}$ was significantly greater than $\mathrm{CaCl}_{2}$ on day $7(p<0.01)$. When the $G^{*}$ data for the hydrogels were normalized to their initial (day 0) measurements, $\mathrm{G}^{*}$ for $\mathrm{CaCO}_{3}$ was significantly greater than $\mathrm{CaCl}_{2}$ or $\mathrm{CaCl}_{2} / \mathrm{PLL}$ for days $1-7$ for both 1 and $5 \mathrm{~Hz}(p<0.01$, Fig. $3 \mathrm{~B}$ and $\mathrm{C})$ and $\mathrm{CaCl}_{2} / \mathrm{PLL}$ was significantly greater than $\mathrm{CaCl}_{2}$ on day $7(p<0.01)$. At day 14 and above, there was no significant difference in $G^{*}$ between the three different conditions, but $G^{*}$ increased significantly for all experimental conditions $(p<0.05)$.

$\delta$ varied with experimental condition and time. $\mathrm{CaCO}_{3}$ had a significantly lower $\delta$ than $\mathrm{CaCl}_{2}$ or $\mathrm{CaCl}_{2} /$ PLL on days 0 and $1(p<0.001$, ANOVA, Fig. 3D). All three conditions varied significantly with time $(p<0.001)$. $\delta$ significantly decreased for all conditions up to 3 days post implant $(p<0.01)$ and then slowly increased up to day 90 , significantly exceeding initial $\delta$ measurements by 2.5 times $(p<0.001)$. When $\delta$ was normalized to the initial measurements for each condition, no difference was detected until day 3 (Fig. 3E and F). On day $3, \mathrm{CaCO}_{3}$ was significantly greater than $\mathrm{CaCl}_{2}(p<0.01)$, and on day $5, \mathrm{CaCO}_{3}$ was significantly greater than $\mathrm{CaCl}_{2}$ and $\mathrm{CaCl}_{2} / \mathrm{PLL}$ $(p<0.01)$ at both 1 and $5 \mathrm{~Hz}$. There was no significant difference at any other time point.

\section{Histology}

In general, $\mathrm{CaCO}_{3}$ and PLL-coated implants were more intact than uncoated $\mathrm{CaCl}_{2}$ implants at 7 days. After day 14, all disks displayed increasing levels of hydrogel fragmentation with collagen around each fragment, increasing the separation of the fragment from the main disk. Macrophages were seen in the tissue around all disks at all of the time points (Fig. 4). After 21 and 90 days, fibrosis and granulation tissue were present in the surrounding connective tissue and were indicative of normal wound healing (Fig. 4).

The encapsulation layer thickness varied with time (Fig. 5). Collagen encapsulation was low initially, then increased significantly at day 14 for $\mathrm{CaCl}_{2}$ and $\mathrm{CaCl}_{2} /$ PLL implants and 21 days for $\mathrm{CaCO}_{3}$ hydrogels $(p<0.05$, ANOVA). Encapsulation thickness was in the range of $15-35 \mu \mathrm{m}$ for all conditions at 14, 21, and 90 days post-implantation. $\mathrm{CaCO}_{3}$ gels had significantly thicker encapsulation than other conditions on day $21(p<0.05)$ but no other significant differences were detected. 
A

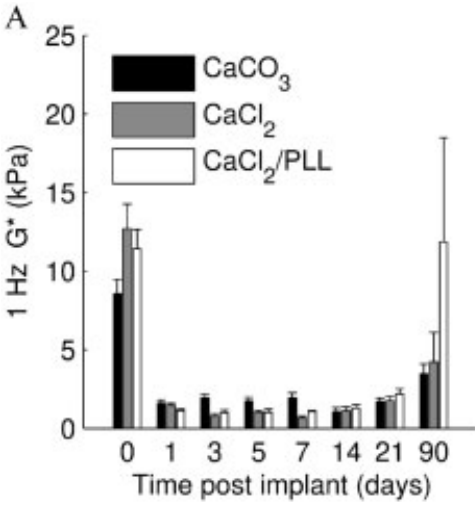

D

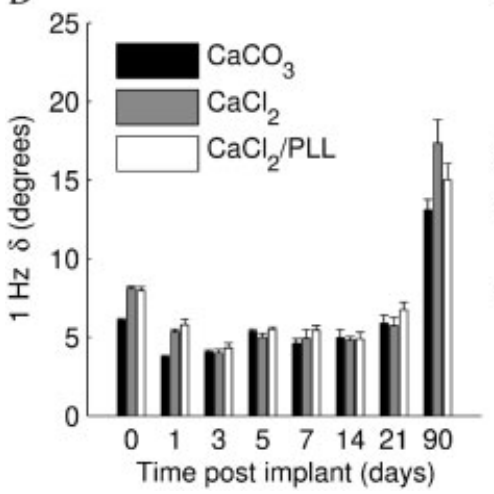

B

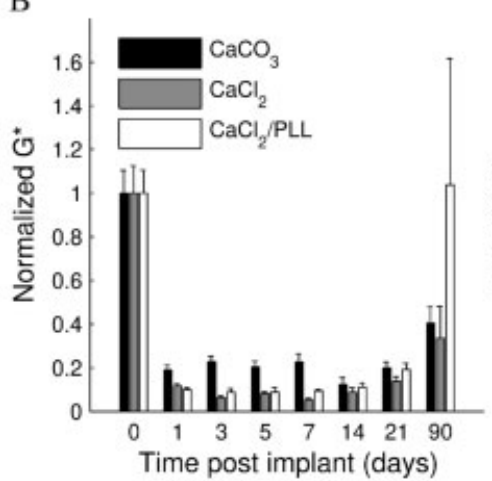

E

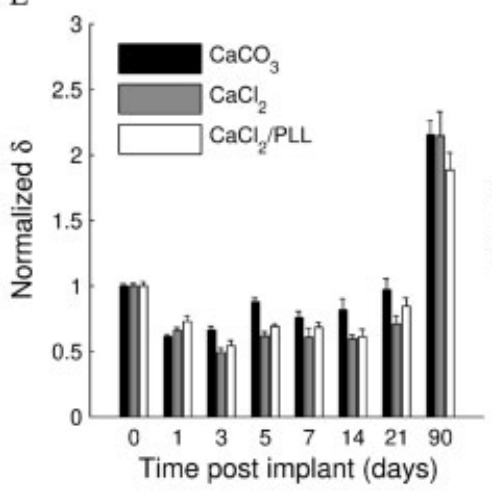

C

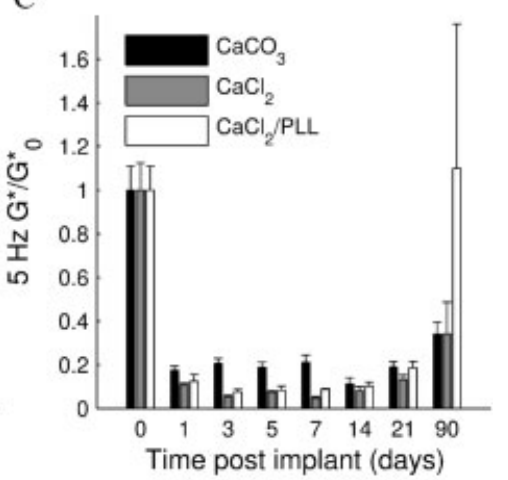

F

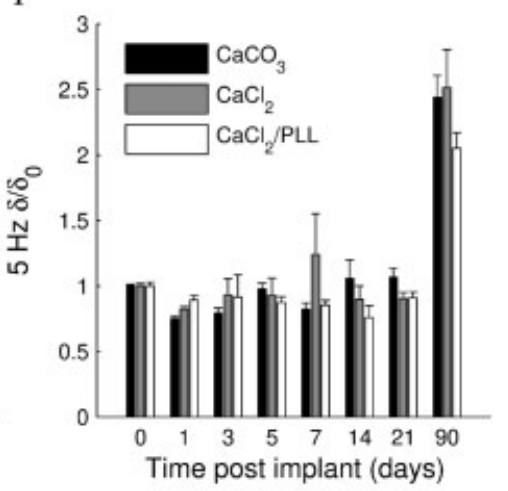

Figure 3. $G^{*}$ and $\delta$ changes over time at $10 \%$ compression. (A)-(C): $G^{*}$ changes over time at 1 and $5 \mathrm{~Hz}$. (D)-(F): $\delta$ changes over time at 1 and $5 \mathrm{~Hz}$. A. Raw data average $G^{*}$ for each time point at $1 \mathrm{~Hz}$. Initially, $G^{*}$ for $\mathrm{CaCO}_{3}$ was smaller than $\mathrm{G}^{*}$ for either $\mathrm{CaCl}_{2}$ or $\mathrm{CaCl}_{2} / \mathrm{PLL}$, but increased by day 7 to become significantly greater than both conditions $(p<0.01)$. After day $14, G^{*}$ increased for all conditions. B. Normalized $G^{*}$ averages for each condition over time at $1 \mathrm{~Hz}^{*} \mathrm{G}^{*}$ for $\mathrm{CaCO}_{3}$ was greater than $\mathrm{CaCl}_{2}$ and $\mathrm{CaCl}_{2} / \mathrm{PLL}$ for all time points except day 90. C. Normalized $\mathrm{G}^{*}$ averages for each condition over time at $5 \mathrm{~Hz}$. $\mathrm{G}^{*}$ for $\mathrm{CaCO}_{3}$ remained greater than $\mathrm{CaCl}_{2}$ and $\mathrm{CaCl}_{2} / \mathrm{PLL}$ for all time points except day 90. D. Raw data average $\delta$ for each time point at $1 \mathrm{~Hz}$. $\delta$ for $\mathrm{CaCO}_{3}$ was lower than $\mathrm{CaCl}_{2}$ and $\mathrm{CaCl}_{2} / \mathrm{PLL}$ until day 5. After day 14, $\delta$ increased for all conditions $(p<0.001)$. E. Normalized $\delta$ averages for each condition over time at $1 \mathrm{~Hz}$. $\delta$ for all conditions decreased until day 3 and then increased to day 90. F. Normalized $\delta$ averages for each condition over time at $5 \mathrm{~Hz}$. $\delta$ changes were smaller at $5 \mathrm{~Hz}$ than $1 \mathrm{~Hz}$ and no significant increase was detected until day 90 for all conditions. $n=5$.

Cell infiltration of the alginate disks varied with time (Fig. 6). Cell infiltration was initially high (scores ranged from 0.9 to 1.5 on day 7 ), and then significantly decreased for all conditions $(p<0.05$, ANOVA). No significant differences in cell infiltration were detected between the conditions at any time point.

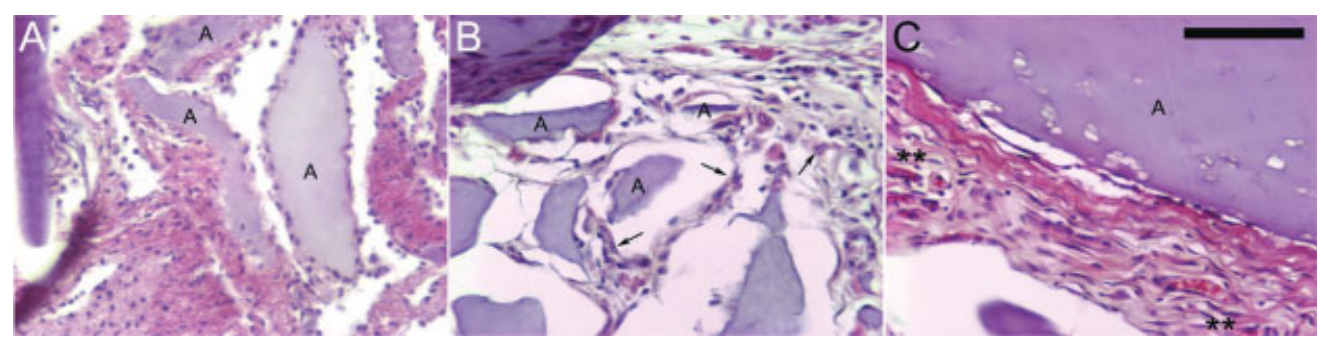

Figure 4. Inflammatory response to alginate over time. Micrographs are at $400 \times$ magnification of HE stained sections. The scale bar in $\mathrm{C}$ represents $50 \mu \mathrm{m}$ in all micrographs. A. $\mathrm{CaCl}_{2} / \mathrm{PLL}$ samples 7 days post implantation. Fragmentation of the alginate (A, not all labeled) has already begun and many macrophages and lymphocytes were present in the tissue and around the alginate. $\mathrm{B}$. $\mathrm{CaCl}_{2}$ reacted alginate, 14 days post implantation. Fibroblasts had begun secreting collagen around the alginate fragments (A, not all labeled). Macrophages were still present in the tissue (indicated by arrows). C. $\mathrm{CaCO}_{3}$ reacted alginate, 90 days post implantation. A thick encapsulation layer was detectable around the alginate (A) filled with fibroblasts and new capillaries which comprise granulation tissue $\left({ }^{*}\right)$. [Color figure can be viewed in the online issue, which is available at www.interscience.wiley.com.] 


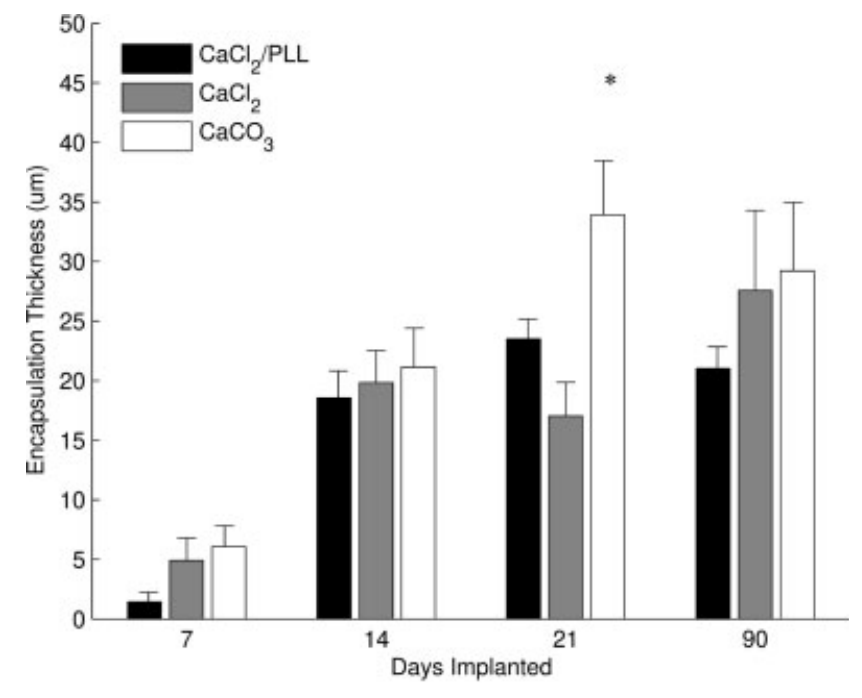

Figure 5. Collagen encapsulation thickness around alginate disks over time. Encapsulation thickness increased over time for all conditions $(p<0.05)$. No difference existed between conditions except day $21 ; \mathrm{CaCO}_{3}$ reacted alginate had a significantly thicker encapsulation layer than $\mathrm{CaCl}_{2} /$ PLL or $\mathrm{CaCl}_{2}\left(p<0.05,{ }^{*} ; n=6\right)$.

\section{DISCUSSION}

To gain insight into the destabilization of alginate for the development of advanced neural interface technologies, we investigated the stability and biological response to alginate in the rat subcutaneous implantation model. The responses demonstrated in this experimental paradigm were expected to be representative of alginate degradation in neural interface applications, albeit a more rigorous test environment. The effects due to in situ gelling versus diffusion gelling and use of a PLL coating were investigated. While all samples' complex moduli decreased $80 \%$ in the first day, the in situ gelled alginate was more stable for the first week of implant. More significantly, the in situ gelled alginate was the only condition that remained within the biologically relevant $G^{*}$ range over the entire 3-month period. This indicates that there is an increased potential of mechanical failure for diffusion gelled alginate during the first week of implant, even in the presence of a PLL coating. However, there were no differences in the histology that would clearly suggest the use of one gelation method over another. Additionally, there appears to be no significant differences between the mechanical stability of the different hydrogels after the first week. Based on these results, the use of in situ gelled alginate is more desirable than diffusion gelled alginate in neural interface applications that require high stability during the first week of implantation.

In situ gelled alginate disks exhibited significantly different weight changes compared to diffusion gelled alginate disks. Although all of the hydrogels exhibited a decrease in weight on the first day, indicating an exudation of liquid, $\mathrm{CaCO}_{3}$ continued to decrease in weight over all time points, indicative of hydrogel degradation over time. ${ }^{56}$ Conversely, $\mathrm{CaCl}_{2}$ and $\mathrm{CaCl}_{2}$ /PLL hydrogels increased in weight for the first week indicating swelling but then decreased in weight, exhibiting similar hydrogel degradation behavior as $\mathrm{CaCO}_{3} .{ }^{56} \mathrm{~A}$ larger weight change for
A

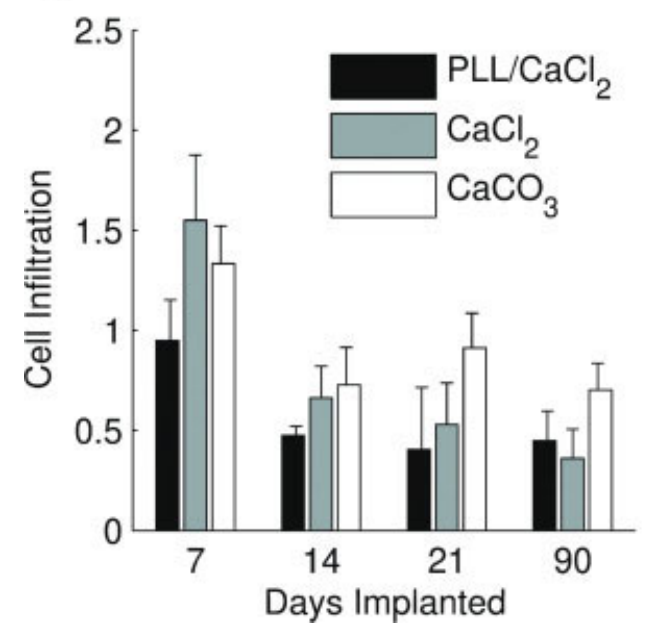

B

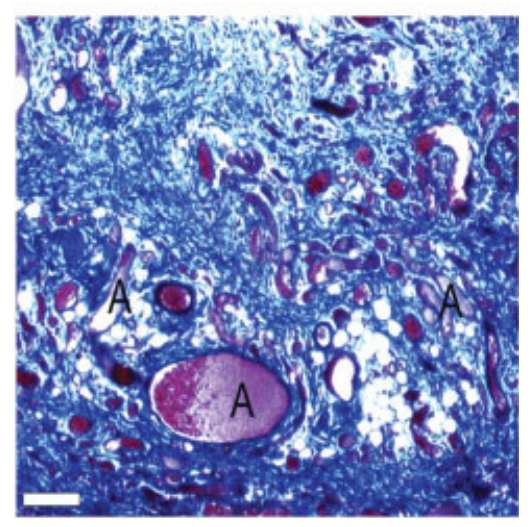

Figure 6. Cellular infiltration of alginate disks over time. (A) Initially, cell infiltration approached moderate levels for all gel conditions $(2 \geq x \geq 1)$, but decreased by day 14 and stabilized at minor infiltration levels $(x \leq 1)$. This decrease from day 7 was significant for all conditions $(p<0.05)$ and there was no significant difference between conditions at any time point, $n=6$. (B) A representative micrograph $\left(\mathrm{CaCl}_{2}, 7\right.$ days post implant) illustrating the varied nature of the infiltration level in a single condition (A indicates alginate fragments). The scale bar represents $200 \mu \mathrm{m}$. [Color figure can be viewed in the online issue, which is available at www.interscience.wiley.com.] 
$\mathrm{CaCl}_{2} /$ PLL hydrogels than $\mathrm{CaCl}_{2}$ hydrogels after 3 months was also detected but is likely due to the loss of the PLL coating, which accounted for initial weight differences between the two experimental conditions. The initial exudation of liquid explanation is supported by the measured decrease in $\delta$ for all of the conditions on day 1 . An exudation of liquid without hydrogel degradation would cause an increase in internal entanglements detected as a decrease in $\delta{ }^{40}$ This may also be responsible for the significant decrease in $G^{*}$ seen on day 1 . The movement of water out of the hydrogel could have changed the underlying structure of the hydrogel enough to cause the observed decrease in $G^{*}$. Based on these observations, the authors hypothesize that the exudation of liquid from the alginate matrix initially causes the hydrogel to lose stability due to a loss of hydrogen bonding within the matrix and a loss of surface tension on the surfaces of the hydrogel.

Alginate degradation over time was not evident in all of the experimental outcomes. The weight change stabilized for all of the experimental conditions between days 21 and 90 . Over these same time points, $G^{*}$ increased, indicating increasing hydrogel stiffness with time. However, this weight stabilization and increase in $G^{*}$ was accompanied by a significant increase in $\delta$ indicating degradation of the hydrogel structure. The lack of agreement between the data can be explained by the replacement of the degrading alginate with fibroblasts and collagen. The formation of granulation tissue amid the remaining degrading alginate fragments between these two time points contributed to the observed weight stabilization, increased $G^{*}$, and decreased $\delta$ for all hydrogel conditions.

Alginate disk fragmentation was an unexpected phenomenon demonstrated by all of the experimental conditions. The fractionation of the implants increased with sequential time points, making mechanical testing increasingly more difficult. All of the alginate pieces collected for a given disk sample were used together for these studies. The authors hypothesize that the fragmentation was due to the combination of destabilization of calcium cross-links by phosphates in the extracellular fluid and phagocytosis of alginate fibers by macrophages.

Due to the pulsation of the brain with heart rate and respiratory rate, the alginate will be subject to oscillatory strain in vivo. The response of alginate to shear is a good indicator of the fatigue resistance and how it will perform in vivo. Brain tissue typically exhibits a complex modulus ranging from 1 to $24 \mathrm{kPa}{ }^{53} \mathrm{It}$ is necessary for alginate to remain in this range to avoid fatigue when used in the central nervous system. $\mathrm{CaCO}_{3}$ reacted alginate disks all remained in this range for all time points, indicating sufficient longterm stability. $\mathrm{CaCl}_{2}$ hydrogels fell below this range on days $3,5,7$ and $\mathrm{CaCl}_{2}$ /PLL hydrogels on days 3 and 5 indicating material fatigue. This is can be attributed to the swelling demonstrated by the hydrogels over this timeframe, which disrupted the hydrogels' underlying chemical interactions and structure. ${ }^{39,57}$ Previously, Strand et al. determined that PLL coated alginate caused a fibrotic reaction more quickly than alginate alone. ${ }^{58}$ Although a similar effect was not detected in the current study, it is possible that low level fibrosis was responsible for the increase in $G^{*}$ over uncoated $\mathrm{CaCl}_{2}$ gels on day 7. Based on these results, diffusion-gelled alginate hydrogels have potential to mechanically fail during the first week of implant when used as a neural interface material.

Cellular infiltration for the alginate disks was due to the large pore size and phagocytosis of the surface alginate fragments. Although alginate is inherently nonsticky and cells are not likely to adhere to the alginate, they are able to treat it as a foreign body. The pore size of gelled, high guluronic acid content alginate is relatively large, $200-400 \mathrm{~nm}^{59}$ This is sufficient to allow phosphate molecules to diffuse into the matrix, thereby destabilizing the ionic interactions that hold the hydrogel together. Additionally, the individual strands of alginate have been measured at 13-26 nm, ${ }^{59}$ small enough for macrophages to begin sequestering portions of the destabilized strands. This combination of destabilization and phagocytosis is responsible for the early cellular infiltration detected histologically.

The results indicate that in situ gelled alginate is more stable in vivo than diffusion gelled alginate during the first week of implantation. Based on initial hydrogel weights alone, diffusion gelled hydrogels would have been hypothesized to have a higher cross-link density and improved stability. The significantly lower weight of $\mathrm{CaCl}_{2}$ reacted hydrogels compared to $\mathrm{CaCO}_{3}$ reacted hydrogels potentially indicated a lower level of water retention in the hydrogel matrix. This was hypothesized to contribute to improved long-term stability of the hydrogels but this is not what was found in the current study. $\mathrm{CaCO}_{3}$ reacted alginate hydrogels had a significantly higher $G^{*}$ and a significantly smaller decrease in $G^{*}$ over the first 7 days $(p<0.01)$. $\mathrm{CaCO}_{3}$ reacted gels additionally exhibited significantly lower $\delta$ measurements initially, indicating a denser distribution of cross-links and entanglements which possibly contributed to the improved stability in vivo. Previously, Kong et al. indicated that high $\mathrm{G}$ alginate was more stable than high $\mathrm{M}$ alginate due to the cross-link density of the high $\mathrm{G}$ alginate. ${ }^{39}$ The high cross-link density allowed the hydrogel to maintain a small pore size and resist tissue growth and replacement of the alginate scaffold used in that study. ${ }^{39}$ This explanation of cross-link density contributing to stability is applicable to the enhanced stability seen with 
$\mathrm{CaCO}_{3}$ gels over $\mathrm{CaCl}_{2}$ gels in the current study. Additionally, in situ gelled alginate did not swell like diffusion-gelled alginate, thereby minimizing the influx of chemical species that disrupt the ionic interaction of $\mathrm{Ca}^{2+}$ with the alginate carboxylic acid residues. $^{39}$ These mechanisms worked together, maintaining the $G^{*}$ of in situ gelled alginate hydrogels within the biologically relevant range for advanced neural interface technologies (1-24 kPa).

The authors gratefully thank Drs. Timothy Becker and Paul Makidon, and Kaylan Brakora for insightful discussions and Neural Intervention Technologies for the use of their rheometer.

\section{References}

1. Becker TA, Kipke DR. ALGEL ${ }^{\circledR}$ as a dural sealant: determination of effects on the sensory-motor cortex in rats. 2003 Sept. 17-21; Cancun, Mexico.

2. Kajiwara K, Ogata S, Tanihara M. Promotion of neurite outgrowth from fetal hippocampal cells by TNF-alpha receptor 1-derived peptide. Cell Transplant 2005;14:665-672.

3. Purcell EK, Kipke DR. In vitro development and characterization of a cortical neural stem cell-seeded alginate scaffold. Society for Biomaterials Annual Meeting and Exposition: New Applications and Technologies, April 26-29, 2006, Pittsburgh, Pennsylvania, USA

4. Purcell EK, Seymour J, Kipke DR. A neural stem cell-seeded open channel probe. Society for Biomaterials Annual Meeting and Exposition: New Applications and Technologies, April 17-21, 2006, San Francisco, CA, USA

5. Kim DH, Abidian M, Martin DC. Conducting polymers grown in hydrogel scaffolds coated on neural prosthetic devices. J Biomed Mater Res A 2004;71:577-585.

6. Vetter RJ, Becker TA, Williams JC, Kipke DR. The use of ALGEL as an artificial dura for chronic cortical implant neuroprosthetics. First International IEEE EMBS Conference on Neural Engineering, March 20-22, 2003; Capri Island, Italy.

7. Nunamaker EA. Alginate as a novel material for duraplasty: Investigation of the material properties, in vivo stability, and sealing capabilities. Doctoral dissertation, University of Michigan, 2006.

8. Becker TA, Kipke DR, Preul MC, Bichard W, McDougall CG. In vivo assessment of calcium alginate gel for endovascular embolization of a cerebral arteriovenous malformation model using the swine rete mirabile. Neurosurgery 2002;51:453-458.

9. Becker TA, Kipke DR, Brandon T. Calcium alginate gel: A biocompatible and mechanically stable polymer for endovascular embolization. J Biomed Mater Res 2001;54:76-86.

10. Draget KI, SkjakBraek G, Smidsrod O. Alginate based new materials. Int J Biol Macromol 1997;21:47-55.

11. Becker TA, Preul MC, Bichard WD, Kipke DR, McDougall CG. Calcium alginate gel as a biocompatible material for endovascular arteriovenous malformation embolization: sixmonth results in an animal model. Neurosurgery 2005;56: 793-801.

12. Aydelotte MB, Thonar EJMA, Mollenhauer J, Flechtenmacher J. Culture of chondrocytes in alginate gel: Variations in conditions of gelation influence the structure of the alginate gel, and the arrangement and morphology of proliferating chondrocytes. In Vitro Cell Dev Biol-Anim 1998;34:123-130.

13. Le Tallec LP, Korwin-Zmijowska C, Adolphe M. Limitations of alginate gels as a culture model for the study of the effects of UVA radiation on human dermal fibroblasts. Cell Biol Toxicol 1997;13:95-102.

14. Nguyen H, Qian JJ, Bhatnagar RS, Li S. Enhanced cell attachment and osteoblastic activity by P-15 peptide-coated matrix in hydrogels. Biochem Biophys Res Commun 2003;311:179186.

15. Haug A. Composition and properties of alginates. Norwegian Institute of Seaweed Research, 1964.

16. Lahaye M. Chemistry and physico-chemistry of phycocolloids. Cahiers Biol Marine 2001;42:137-157.

17. Haug A, Smidsrod O. Effect of divalent metals on properties of alginate solutions. 2. Comparison of different metal ions. Acta Chem Scand 1965;19:341-351.

18. Wideroe H, Danielsen S. Evaluation of the use of $\mathrm{Sr}^{2+}$ in alginate immobilization of cells. Naturwissenschaften 2001;88: 224-228.

19. Smidsrod O, Haug A. Effect of divalent metals on properties of alginate solutions. I. Calcium oons. Acta Chem Scand 1965;19:329

20. Grant GT, Morris ER, Rees DA, Smith PJC, Thom D. Biological interactions between polysaccharides and divalent cations-Egg-box model. Febs Lett 1973;32:195-198.

21. Amsden B, Turner N. Diffusion characteristics of calcium alginate gels. Biotechnol Bioeng 1999;65:605-610.

22. Ishikawa K, Ueyama Y, Mano T, Koyama T, Suzuki K, Matsumura $T$. Self-setting barrier membrane for guided tissue regeneration method: initial evaluation of alginate membrane made with sodium alginate and calcium chloride aqueous solutions. J Biomed Mater Res 1999;47:111-115.

23. Kuo CK, Ma PX. Ionically crosslinked alginate hydrogels as scaffolds for tissue engineering: Part 1. Structure, gelation rate and mechanical properties. Biomaterials 2001;22:511-521.

24. Liu XX, Qian LY, Shu T, Tong Z. Rheology characterization of sol-gel transition in aqueous alginate solutions induced by calcium cations through in situ release. Polymer 2003;44:407412.

25. Mammarella EJ, Rubiolo AC. Crosslinking kinetics of cationhydrocolloid gels. Chem Eng J 2003;94:73-77.

26. Shchipunov YA, Koneva EL, Postnova IV. Homogeneous alginate gels: Phase behavior and rheological properties. Polym Sci Ser A 2002;44:758-766.

27. Smidsrod O, Haug A. Dependence upon gel-sol state of ionexchange properties of alginates. Acta Chem Scand 1972;26: 2063.

28. Yamagiwa K, Kozawa T, Ohkawa A. Effects of alginate composition and gelling conditions on diffusional and mechanical-properties of calcium-alginate gel beads. J Chem Eng Jpn 1995;28:462-467.

29. Wang ZY, Zhang QZ, Konno M, Saito S. Sol-gel transition of alginate solution by the addition of various divalent-cations-a rheological study. Biopolymers 1994;34:737-746.

30. Wang ZY, Zhang QZ, Konno M, Saito S. Sol-gel transition of alginate solution by addition of calcium-ions-alginate concentration-dependence of gel point. J Phys II 1993;3:1-7.

31. Blandino A, Macias M, Cantero D. Formation of calcium alginate gel capsules: Influence of sodium alginate and $\mathrm{CaCl}_{2}$ concentration on gelation kinetics. J Biosci Bioeng 1999;88: 686-689.

32. Bienaime C, Barbotin JN, Nava-Saucedo JE. How to build an adapted and bioactive cell microenvironment? A chemical interaction study of the structure of Ca-alginate matrices and their repercussion on confined cells. J Biomed Mater Res A 2003;67:376-388.

33. Wang L, Shelton RM, Cooper PR, Lawson M, Triffitt JT, Barralet JE. Evaluation of sodium alginate for bone marrow cell tissue engineering. Biomaterials 2003;24:3475-3481.

34. Strand BL, Morch YA, Skjak-Braek G. Alginate as immobilization matrix for cells. Minerva Biotecnol 2000;12:223-233. 
35. Li RH, Altreuter DH, Gentile FT. Transport characterization of hydrogel matrices for cell encapsulation. Biotechnol Bioeng 1996;50:365-373

36. Kulseng B, Thu B, Espevik T, SkjakBraek G. Alginate polylysine microcapsules as immune barrier: Permeability of cytokines and immunoglobulins over the capsule membrane. Cell Transplant 1997;6:387-394.

37. Rokstad AM, Holtan S, Strand B, Steinkjer B, Ryan L, Kulseng B, Skjak-Braek G, Espevik T. Microencapsulation of cells producing therapeutic proteins: Optimizing cell growth and secretion. Cell Transplant 2002;11:313-324.

38. Draget KI, Ostgaard K, Smidsrod O. Homogeneous alginate gels: A technical approach. Carbohydr Polym 1990;14:159178.

39. Kong HJ, Alsberg E, Kaigler D, Lee KY, Mooney DJ. Controlling degradation of hydrogels via the size of cross-linked junctions. Adv Mater 2004;16:1917-1921.

40. LeRoux MA, Guilak F, Setton LA. Compressive and shear properties of alginate gel: effects of sodium ions and alginate concentration. J Biomed Mater Res 1999;47:46-53.

41. King A, Sandler S, Andersson A. The effect of host factors and capsule composition on the cellular overgrowth on implanted alginate capsules. J Biomed Mater Res 2001;57: 374-383.

42. Kulseng B, Thu B, Espevik T, Skjak-Braek G. Alginate polylysine microcapsules as immune barrier: permeability of cytokines and immunoglobulins over the capsule membrane. Cell Transplant 1997;6:387-394.

43. Gugerli R, Cantana E, Heinzen C, von Stockar U, Marison IW. Quantitative study of the production and properties of alginate/poly-L-lysine microcapsules. J Microencapsul 2002; 19:571-590

44. Strand BL, Ryan TL, In't Veld P, Kulseng B, Rokstad AM, Skjak-Brek G, Espevik T. Poly-L-Lysine induces fibrosis on alginate microcapsules via the induction of cytokines. Cell Transplant 2001;10:263-75.

45. King A, Lau J, Nordin A, Sandler S, Andersson A. The effect of capsule composition in the reversal of hyperglycemia in diabetic mice transplanted with microencapsulated allogeneic islets. Diabetes Technol Ther 2003;5:653-663.

46. King A, Sandler S, Andersson A. The effect of host factors and capsule composition on the cellular overgrowth on implanted alginate capsules. J Biomed Mater Res 2001;57:374-383.

47. Rokstad AM, Holtan S, Strand B, Steinkjer B, Ryan L, Kulseng B, Skjak-Braek G, Espevik T. Microencapsulation of cells producing therapeutic proteins: optimizing cell growth and secretion. Cell Transplant 2002;11:313-324.

48. Benson JP, Papas KK, Constantinidis I, Sambanis A. Towards the development of a bioartificial pancreas: effects of poly-Llysine on alginate beads with BTC 3 cells. Cell Transplant 1997;6:395-402.

49. Gugerli R, Cantana E, Heinzen C, Von Stockar U, Marison IW. Quantitative study of the production and properties of alginate/poly-L-lysine microcapsules. J Microencapsul 2002; 19:571-590.

50. Orive G, Hernandez RM, Gascon AR, Calafiore R, Chang TM, De Vos P, Hortelano G, Hunkeler D, Lacik I, Shapiro $\mathrm{AM}$, et al. Cell encapsulation: promise and progress. Nat Med 2003;9:104-107.

51. Strand BL, Gaserod O, Kulseng B, Espevik T, Skjak-Baek G. Alginate-polylysine-alginate microcapsules: effect of size reduction on capsule properties. J Microencapsul 2002;19:615-630.

52. Donnelly BR, Medige J. Shear properties of human brain tissue. J Biomech Eng: Trans Asme 1997;119:423-432.

53. Kang BC, Kang KS, Lee YS. Biocompatibility and long-term toxicity of InnoPol implant, a biodegradable polymer scaffold. Exp Anim 2005;54:37-52.

54. Kyriakides TR, Leach KJ, Hoffman AS, Ratner BD, Bornstein P. Mice that lack the angiogenesis inhibitor, thrombospondin 2, mount an altered foreign body reaction characterized by increased vascularity. Proc Natl Acad Sci USA 1999;96:44494454.

55. Bos GW, Hennink WE, Brouwer LA, den Otter W, Veldhuis $\mathrm{TF}$, van Nostrum CF, van Luyn MJ. Tissue reactions of in situ formed dextran hydrogels crosslinked by stereocomplex formation after subcutaneous implantation in rats. Biomaterials 2005;26:3901-3909.

56. Bajpai SK, Sharma S. Investigation of swelling/degradation behaviour of alginate beads crosslinked with $\mathrm{Ca}^{2+}$ and $\mathrm{Ba} 2+$ ions. React Funct Polym 2004;59:129-140.

57. Wang XW, Spencer HG. Calcium alginate gels: Formation and stability in the presence of an inert electrolyte. Polymer 1998;39:2759-2764.

58. Strand BL, Ryan TL, In't Veld P, Kulseng B, Rokstad AM, Skjak-Brek G, Espevik T. Poly-L-Lysine induces fibrosis on alginate microcapsules via the induction of cytokines. Cell Transplant 2001;10:263-275.

59. Veluraja K, Atkins EDT. Electron-microscopic study of guluronate-rich alginate. Carbohydr Res 1989;187:313-316. 